\title{
“I AM YOUR PERFECT ONLINE PARTNER" ANALYSIS OF DATING PROFILES USED IN CYBERCRIME
}

\author{
Christian Kopp a, James Sillitoe ${ }^{b}$, Iqbal Gondal c \\ abc Federation University Australia \\ Corresponding email: ckopp@students.federation.edu.au
}

\begin{abstract}
Internet Online Dating has become an influential mainstream social practice facilitating the finding of a partner. Unscrupulous operators have identified its potential and started to use this platform for identity theft in form of so called Online Romance Scams. Quickly, this cybercrime has become very successful and thus, an increasing threat in the social networking environment. So far, very little is known about its structure and the reason for its success, and this needs to be known in order to be able to fight it efficiently. This research tries to contribute to this knowledge, and argues that scammers use so-called 'Love Stories', which represent personal affinities related to romantic relationships, to their benefit when tailoring common narratives as part of fraudulent online profiles to attract their victims. We look at these different types of 'Personal Love Stories' and discuss how they can be used in this type of scam, followed by a qualitative analysis of fraudulent profiles from three different international websites to examine this assumption.
\end{abstract}

Keywords: Internet Crime, Online Dating \& Love Stories.

\section{Introduction}

Cybercrime is a major interdisciplinary concern thriving on the opportunities that information and communication technologies (ICT) offer [8]. Activities, which fall under the cyber-crime category, range from the use of malware to gain sensitive information [1] to the use anonymity of internet channels to trick people into sending money [18]. In this area are the Online Romance Scams which have emerged as a significant cybercrime in recent years [22]. Stabek [19] has classified Romance Scams as an advanced, sophisticated and therefore, a very dangerous type of scam. A considerable concern here is that the extent of these cyber scams appears to be growing [5]. Indeed, given the popularity of the online dating market and the significant economic implications of this area, it is perhaps not surprising that this has become a key focus of fraudsters and scammers [12] [16]. In 2014, it was reported that dating and romance scams remained in the number one position in terms of financial losses, showing an estimated loss of \$27 million, but it has since increased more than 10 per cent in 2015 [3]. In addition, earlier figures suggested that victims of this type of fraud have lost an average of $\$ 17,000$ per person, an amount which is almost twice that of victims involved in other advanced fee scams [17].

Despite the significant social risks inherent in this crime and its great increase in recent years [13], surprisingly little research has been conducted on this new scam, and this current research is a timely contribution to this area.

The crime is based on two key parts. Firstly, a fake profile is set up by the scammer on either a legitimate dating site, a social networking site, or in a chat room. This profile provides the scammer access to a legitimate website, and enables them to contact other website users. 
Secondly, there is an initiating conversation between the scammer and the victim, which implements the structure of the scam.

When scammers post a fake profile on a legitimate site, they often use high quality, professional looking photos, in combination with an attractive profile description, to attract potential victims [9]. Once contact is established, the scammer will direct the interaction to an external channel, usually an email outside of the dating website. They do this because there is always the risk that their profile would be identified as fraudulent and suspended from the dating site. After the scammer has directed the contact to an external channel, they institute constant contact to deepen the relationship, and to build trust with the victim. Usually, after a relatively short period of time, the scammer begins declaring their love for the victim.

Parallel to all the efforts to develop the relationship, the scammer will casually report events related to another invented story which will be suitable for building a plausible frame for a subsequent request for money [10]. There are different types of stories used: one common example is that the scammer has to travel to another country for some special event or unexpected tragedy, such as a sudden death [6]. Once the scammer believes that the victim is committed to the relationship, they ask the victim to send money to them or a third party, usually via a wire transfer service.

On the surface, the Romance Scam looks quite simple and somewhat transparent, but this raises the obvious question - why do victims become so deeply involved and keep sending money to the scammer against all warnings?

This research contributes to existing knowledge by analysing the structure of fraudulent profiles used in the Online Romance Scam. Further, it investigates how personal romantic affinities drafted as narratives in so called 'Love Stories' [21] are used in fraudulent profiles published on the internet and how they can be distinguished according to the origin of the scammer. One essential part of this crime includes identity theft, and it regularly attempts to involve the victim in a money laundering activity. This relationship also indicates implication to these types of cybercrimes and contributes to existing knowledge related them. We contend that the findings of this research will contribute to a deeper understanding of the operation of this cybercrime, and will provide information about the structure of fraudulent profiles. This information can then be used to more quickly identify an online profile as a scam, which will help to prevent potential victims opening communications with a scammer with a fraudulent profile, and thus avoiding the possible suffering of emotional or financial harm.

\section{Nigerian Letter compared to Romance scam}

To investigate the Romance Scam, we will generalise the insights which have been developed in understanding the Nigerian letter scams to better understand the techniques used in these newer scams. In a similar way to the "The Nigerian letter", we propose that the scam techniques appeal to strong emotions, which are clearly involved in Romantic relationships [15]. The Nigerian letter is an advanced fee fraud, in which a very high sum of money is promised to the victim. But, the victim must first pay a number of fees in order to procure the grand sum [2]. The initial contact is an email from an important-sounding officer or public representative such as a lawyer, government official or former politician. The scam progresses to the next level if the recipient responds via email or telephone. Then they are asked to pay a fee. This can be a stamp duty fee, or any other fee which appears reasonable, to advance to the next stage. After the victim has paid the fee, they are instructed to pay another fee, for example to facilitate document 
processing. In the correspondence, the victim is constantly asked to pay any additional fee, which is declared to be the last request which is necessary to be payed to release the money. This process continues till the victim stops sending money [7].

Dyrud has identified the techniques that make the scam successful. Firstly, the scam uses themes which have a deep emotional appeal, such as appeal to religious sensibilities, notions of social justice for charitable donations or humanitarian aid in current disasters. Using these themes in combination with the offering significant return of funds builds a strongly emotional and complex scenario involving pity, trust and greed [6]. We can assume that Romance scams also appeal to very strong emotions since romantic relationships, personal attachment and romantic love clearly involve multiple emotions such as jealousy, excitement, hope, sadness, joy.

Table 1: Emotions in Nigerian Letter and Romance Scam

\begin{tabular}{|l|l|}
\hline Nigerian Letter & Romance scam \\
\hline Pity & Jealousy \\
\hline Greed & Sadness \\
\hline Trust & Hope \\
\hline Sorrow & Disappointment \\
\hline
\end{tabular}

In Table 1, the emotions addressed by the romance scam are compared with emotions addressed by the Nigerian letter. It appears that the Romance scam attempts to use a larger and stronger set of involved emotions in order to engage deeper commitment of the victim. Further, Cukier [7] has identified the genres used in the Nigerian letters which support the appeal to these strong emotions. The letters apply narratives which invoke well known cultural myths, including "rags to riches" stories, and other familiar motifs, and include a typical hero, plot and outcome. The character of the writer portrayed in the Nigerian letter scam is often one of the archetypal characters taken from the motifs from folklore and fairy tales, such as 'Robin Hood' or the 'damsel in distress'. These mythical narratives allow the victim to play complementary roles; they can play the role of the rescuer or the lucky finder of a lost treasure.

Following the strategy of the Nigerian Letter, we assume that the Romance Scam also uses narratives which invoke strong emotions.

Table 2: Narratives in Nigerian Letter and Romance Scam

\begin{tabular}{|l|l|}
\hline Nigerian Letter & Romance scam \\
\hline Windfall fortunes & Perfect Partner \\
\hline Lucky finder of lost treasure & Russian beauty \\
\hline Rescuer of princess & Real religious person \\
\hline Hero & Talented but poor artist \\
\hline The benevolent & Successful businessman \\
\hline Sympathiser & Exotic princess \\
\hline The good thief & $\begin{array}{l}\text { Handsome and trustful soldier in higher } \\
\text { rank }\end{array}$ \\
\hline
\end{tabular}

In Table 2, we compare narratives used in Nigerian Letter to narratives which can be used by the Romance Scam. Table 2 indicates that, in these complex arrangements, the Romance scam 
deliberately uses situations that lead to stronger psychological "tools" compared to the Nigerian Letter. In the next section, we will look closely at the different narratives which can be used to build the basis of a romantic relationship.

\section{Narratives in romantic relationships}

In order to understand what makes a romance scam successful, we need to examine the elements of romantic relationships, in particular, what motivates an individual to choose a relationship and what makes a relationship successful. Since scams require a sequence of successful interactions aimed at building attachments, the timeline of relationship building and maintenance is critical. Sternberg [20] presents five major groups of stories.

Table 3 summarises these love stories types and their related narratives, which are more fully explained in the following section.

Table 3: Narratives in Nigerian Letter and Romance Scam

\begin{tabular}{|l|l|}
\hline Love Story Group/ Lovestory & Narrative \\
\hline (Asymmetry) Teacher/Student & Power on cultural grounds \\
\hline (Object) Collection & Implied value urges to care \\
\hline (Coordination) Traveler & Collective planning \\
\hline (Narrative) Fairy tale, Cookbook & $\begin{array}{l}\text { Cultural guidelines } \\
\text { (Fairy tales, Magazines) } \\
\text { (Culture dependent gender narratives } \\
\text { as: Dominant man and dependent } \\
\text { woman) }\end{array}$ \\
\hline (Genre) War, Humor & $\begin{array}{l}\text { Atmosphere where we grow up is } \\
\text { important. Narrative from constant } \\
\text { fight or fun. }\end{array}$ \\
\hline
\end{tabular}

\section{1 Asymmetrical Stories}

Asymmetrical stories can be characterized through a strong complementary behaviour between the partners in the relationship. It exists as an asymmetry between the partners which is the basis of the relationship. It usually implicates a misbalance of power, where one partner controls most, or all, of the power. Asymmetrical Stories seem to be a good basis for a scam, because once the scammer has achieved this powerful role, they can customise it for each potential victim.

\section{2 Object Stories}

Sternberg divides object stories into two sub-types. In the first, one partner is somehow seen as an object by the other partner, whilst in the second, the whole relationship is an object.

\section{3 Coordination Stories}

In coordination Stories, the partners work together to create or maintain something. For example, in the Travel Story, love is seen as a journey. This seems to be a good story to be used for a scam, since it appeals to the strong emotion of 'curiosity'. It is the prospect of change, or the experience of something new, that holds appeal for the victim. It involves them in a stream of planning, occupying the victim in the expectation to create something, where the target is not as important as the journey. 


\section{4 Narrative Stories}

These are stories, which require the partners to follow a text or story from the outside. The Fantasy Story is a classical love story, and is probably the best narrative story for a scam. It involves strong romantic emotions in a fantasy way, and people who hold this story are likely to view their partner as a 'dream which came true'. They can easily imagine a fantasy world, and it is easy for a scammer to build upon this imagined story by inventing details and continually developing the conceit. The profile is very easy to draft in terms of a character such as a prince or princess, and fits well into very familiar, and usually desirable, narrative patterns.

\section{5 Genre Stories}

The last are genre Stories, which involve a particular mode or way of engaging in the relationship. In Genre Stories, only the Mystery Story appears to be useful for a scam. It involves a certain amount of 'excitement' of the unknown. Since relationships often begin with a sense of mystery, this element could appeal to a wide range of potential victims.

\section{Analysis of fraudulent online profiles}

The profile texts were read several times. Subsequently, key paragraphs were marked on the basis of their revealed information, and the information was examined in order to find a common structure of the profile description, the type of language used and its style. We then interpreted the intended message to the reader of the profile in relation to the love story which was implemented in the scam.

\section{1 Data}

The data set used for this analysis consists of fraudulent profiles published on two dating and one scam warning internet page. These profiles present lists of known scam profiles, intending to warn other users. All three website are a free service to international users.

\section{1. 2. Russian Scammers}

The first source consisted of 298 female profiles from Russian Scammers without a picture. This dataset is interesting from the point of view of the large number of profiles, allowing us to analyse the textual structure of the profile description. We call this source the "Russian Scammers".

\section{1. 2. African Scammers}

The second source is a set of 37 fraudulent profiles. These scammers appear to originate from Africa, but pretend to be from different parts of the world. This data set is interesting because it provides warnings for different genders and may also reveal differences in how scammers from different origin countries develop and present their scam profiles. We call this source the "African Scammers".

\section{1. 2. Advanced Profiles}

For the third source, we reviewed ten male and female profiles, which came with a photo and a description. The source is a scam warning page and consists of collected profiles from dating websites and social web pages such as Facebook. We call this source the "Advanced Profiles".

\section{2. Method}

The profile texts were read several times. Subsequently, key paragraphs were marked on the basis of their revealed information and the information was examined in order to find a 
common structure of the profile description, the type of language used and its style. We then interpreted the intended message to the reader of the profile in relation to the love story which was implemented in the scam.

\section{Findings}

The data set used for this analysis consists of fraudulent profiles published on two dating and one scam warning internet page. These profiles present lists of known scam profiles, intending to warn other users. All three websites are a free service to international users.

\section{1. Russian Scammer}

The profile description contained a short paragraph with four parts. They contain a selfdescription, followed by hobbies, motivation to look for a partner online and finally by the character for which they are looking. The first part contained a personal description.

Hello! My name is Irina. I live in Russia, in small but beautiful city under name Cheboksary.

Normally, the scammer introduced the character as a kind of 'Cinderella' or 'Sleeping Beauty', who is waiting to be found - an undetected beauty who is still available. The character is presented in a humble way, as simple but very cheerful and gentle. They typically they come from a 'small city' and express a sense of loneliness. The small city location subtly suggests a reason why the 'beauty' has not been detected previously. The profile also expresses a sense of 'hope', to emphasize their miserable situation, from which they want to be rescued by their 'prince'. Physical appearance is always described as outstanding good. Sometimes, they describe their age and weight, which are usually in the perfect range. Very rarely do they mention education or their current work situation.

The second part describes what the character likes, and what their hobbies are.

Basic my passion is a romanticism of the nature: a wood, the rivers, a dust of roads, boundless horizon, a rain, a wind, star Nights.

The hobbies are usually ordinary, like reading, going to the cinema and meeting friends. Very often, the character also likes sport. This supports the impression of physical health and an attractive body.

The third part covers the reason why the character is looking online for a partner. They use common clichés (narratives), such as having had bad experiences with local men, loneliness or lack of opportunities to meet suitable people. In this context they also emphasize their serious intention to find a real partner, and their willingness to build an honest relationship, which should lead to a loving family which includes children, but at a later point of time.

My life with Russian men has not developed, I hope to find the love in the Internet.

The fourth part describes the character of the person they are looking for. The character is described with generic attributes as respectful and gentle. They emphasise that they are looking for someone 'normal' and not 'perfect'. Many profiles complain that the men in their previous relationships could not take responsibility, and they thus, directly ask for a strong man who knows how to work together with a woman.

I wish to find to myself worthy, serious the man which too is lonely and too the desire to get has family 
The language in the Russian profiles shows many obvious spelling, syntactic and grammatical errors. In this case of young, female profiles, the intention is to make the reader feel sympathetic to the apparent isolation implied by the profile, but also to make the victim feel superior and stronger. The style is usually humble and soft.

These Russian profiles use the 'Cinderella' character as a base type to address romantic emotions and to direct a Fantasy Story. We also found some sexual hints or even a slight pornographic touch indicating an offer or highlighting availability. These profiles address sexual emotions and suggest a softer version of a Pornographic Story. The search for a normal but strong character as partner addresses people with a liability to dominate their partner, who is not necessarily confident enough to establish this type of situation in real life. It clearly addresses the strong emotion 'power' and leads in the direction of a Government Story.

\section{2. African Scammer}

The pictures from male profiles show normal to average looking men. They appear to be stolen from personal social websites and the female pictures usually show very attractive women. The photos are very likely stolen from professional web sites and magazines.

The profiles also showed the previously described four-part structure: self-description, hobbies, motivation, and target description. In the self-description, they claim to be from wealthy families with high influence. We have noticed that especially the females appear very confident and independent, with no interest in financial support. This creates the illusion of a respectful and important person and addresses emotions as 'loyalty' which builds a good basis for the History Story. Male profiles were often presented from the perspective of tragedy where the man's close family has died through accidental circumstances. This appeals to emotions 'pity' and 'sympathy', and suggests a Recovery or Sacrifice Story.

Related to their Likes and hobbies, the female profiles mostly focus on music, as well as fitness and sports activities. Many profiles also claimed to have interests in unusual activities such as motor sports or soccer, while the male profiles were generally not interested in these activities. They instead focus on fitness, swimming, cooking or even romantic dancing. This indicates that the African scammers tried to build relatively unrealistic picture of a perfect partner who shares exactly the same gender-related interests or hobbies as the victim.

Both male and female profiles often explained their motivation with an appeal to social wisdom, with sayings such as 'to love and to be loved are very important in life'.

As target characters, male and female profiles look for loving and caring partners. Together with the described tragic circumstances used by the male profiles, the picture of a Recovery or Sacrifice Story is deepened with the search for victims who are more likely to share pity and sympathy.

The language is very bad, containing many grammatically and syntax errors. The bad language often contradicts the details of the presented story, where the scammer pretends to be a highly educated person from a country with an English background.

The style of the male Africans is very often affected by religion. They use phrases like "Trust in God", "I really do believe in GOD" or "with a fear of God". This creates a trustful atmosphere which contributes to a good communication between scammer and victim, and further suits to introduce a Religion Story. 


\section{3. Advanced Profiles}

These profiles were posted on several dating websites and on Facebook. The fact that they are posted on Facebook increases the impression of a real person, who is genuinely looking for friends and social relationships rather than a romantic partnership. In this case, there is less initial commitment involved in contacting this profile, which encourages more victims to engage with the scammer.

The pictures of the male profiles look average. In many cases, they look as they were self-taken with a mobile phone camera or as a good shot taken by a friend. They also use stolen photos which show the person at university graduations or during a military decoration ceremony. The pictures from females show attractive women. They appear to be stolen from personal social web pages, and look more like a beauty from the neighborhood or an attractive school girl rather than one taken from a professional source.

When the profile is posted on a dating website, the structure also follows the four parts which we described before. In the self-description, the male profiles also provide stories about their strokes of fate where they lost their family, and this situation directs the relationship to a Recovery- or Sacrifice Story.

As motivation, they bring wise slogans to bear, as, for example, 'how important it would be to have family' and consequently as a target character they look for the right woman to share their life. The presentation becomes different when the profile is posted on a social web page. Here, they use the website functions to describe hobbies and interests with links. On outstanding feature is that they have a big range of interests, and not necessarily gender-oriented ones.

The language of the male profiles is very bad, and again contrasts with the profile description which claims to be a highly educated person in a responsible role as army officer. The language of the female profiles is relative good which is somewhat different to the previous cases. We suspect it might indicate a different trend of scam.

The style of the presentation follows the same style what we described previously. They include God and try to express a liability to God, which indicates an origin from Africa.

\section{Conclusions}

This article contributes to existing knowledge by analysing the structure of fraudulent profiles used in the Romance Scam. We assume that elements of so called love stories are carefully tailored into the fraudulent profiles to address strong emotions. We then have identified personal love stories which can be used for a romance scam. The analysis clearly shows that personal love stories are built into fraudulent profiles of the romance scam. The most frequently used stories are the Fantasy Story and the Recovery Story followed by the Religion Story and History Story. The exploration also showed differences in using the love stories according to the gender. The Fantasy Story dominated in the presentation of the female profiles. It is sometimes combined with the Government Story. This supports the expected gender-related role as superior man. The male profiles also use elements of the Fantasy Story, but usually it is not as strongly drafted as in the female profiles and is often combined with a cocktail of other stories as Religion, Government, Recover and Traveler Stories. The fantasy story can easily be combined with these other stories by equipping the character with the right attributes. As a result, the profile reaches a larger audience by addressing several personal love stories. 
The exploration also showed that there are differences in using the love stories according to the origin of the scam. The African profiles appear more confident and demanding combined with desirable, but unrealistic offers. The Russian profiles prefer a softer more humble presentation. It is important to note that the scammers operate not only on dating websites but, also on social websites. They can build virtual persons by using the same names and same profile descriptions on different website, which increases the operating range, provides additional communication channels and increases the illusion of a real person.

Limitations of this approach arise from ethical considerations related to the usage of the public available data from the internet for research [14]. Following ethical guidelines, the approach imposes restrictions in order to conform to the three principles of Autonomy, Benefits against Risks and Justice, proposed by the influential Belmont Report [4].

This strategy needs further investigation, and will form part of our further research in which a deeper analysis could use data mining methods as described by Pan et al.[10].

\section{Acknowledgement}

This article contributes to existing knowledge by analysing the structure of fraudulent profiles that I would like to acknowledge. I would like to thank my initial principal supervisor, Professor Paul Watters and associated supervisor Dr Robert Layton for supporting my research in completing my work, presented in the paper. 


\section{References}

i. Alazab, Mamoun, Sitalakshmi Venkatraman, Paul Watters, and Moutaz Alazab. "Zero-day malware detection based on supervised learning algorithms of api call signatures." In Proceedings of the Ninth Australasian Data Mining Conference-Volume 121, Australian Computer Society, Inc., 171-182.

ii. Allen, G. N., Burk, D. L., \& Davis, G. B. (2006). Academic data collection in electronic environments: Defining acceptable use of internet resources. MIS Quarterly, 30(3), 599-610.

iii. Australian Competition and Consumer Commission (2015) Targeting scams: Report of the ACCC on scam activity 2014. From: https://www.acc.gov.au/publications/targeting-scams-report-onscamactivity/targeting-scams-report-of-the-accc-on-scam-activity-2014

iv. Belmont, R. (1979). Ethical principles and guidelines for the protection of human subjects of research. Washington, DC: Department of Health, Education, and Welfare.

v. Bergiel, B. J., Bergiel, E. B., \& Balsmeier, P. W. (2008). Internet cross border crime: A growing problem. Journal of Website Promotion, 3(3-4), 133-142.

vi. Bowlby, J. (1997). Attachment and loss: Vol. 1. Loss. New York: Basic Books

vii. Buchanan, T., \& Whitty, M. T. (2014). The online dating romance scam: causes and consequences of victimhood. Psychology, Crime \& Law, 20(3), 261-283.

viii. Choo, K. K. R. (2011). The cyber threat landscape: Challenges and future research directions. Computers \& Security, 30(8), 719-731.

ix. Ellis, B. J., \& Symons, D. (1990). Sex differences in sexual fantasy: An evolutionary psychological approach. Journal of Sex Research, 27(4), 527-555.

x. Ellison, N. B. (2007). Social network sites: Definition, history, and scholarship. Journal of Computer-Mediated Communication, 13(1), 210-230.

xi. Fair, J. E., Tully, M., Ekdale, B., \& Asante, R. K. (2009). Crafting Lifestyles in Urban Africa: Young Ghanaians in the World of Online Friendship. Africa Today 55, 28-49. .

xii. Koon, T. H., \& Yoong, D. (2013). Preying on lonely hearts: A systematic deconstruction of an internet romance scammer's online lover persona. Journal of Modern Languages, 23, 28-40.

xiii. Kopp, C., Sillitoe, J., Gondal, I., \& Layton, R. (2015). Ethical considerations when using online datasets for research purposes. In Layton, Robert, and Paul A. Watters. Automating open source intelligence: Algorithms for OSINT, Syngress, 131-158.

xiv. Kopp, C., Sillitoe, J., Gondal, I., \& Layton, R. (2016). The Role of Love stories in Romance scams. International Journal of Cyber Criminology, 10(1).

xv. Rathinaraj, D., \& Chendroyaperumal, C. (2010). Financial Fraud, Cyber Scams and India-A Small Survey of Popular Recent Cases. Cyber Scams and India-A Small Survey of Popular Recent Cases. (May 12, 2010). 


\section{Asia Pacific Journal of Advanced Business and Social Studies \\ ISBN (eBook): 9780994365675 I ISSN : 2205-6033 \\ Year: 2017 , Volume: 3, Issue: 2}

xvi. Ross, S., \& Smith, R. G. (2011). Risk Factors for Advance Fee Fraud Victimisation. Trends \& Issues in Crime and Criminal Justice 420.

xvii. Sharifi, M., Fink, E., \& Carbonell, J. G. (2011, October). Detection of internet scam using logistic regression. In Systems, Man, and Cybernetics (SMC), IEEE International Conference (pp. 21682172).

xviii. Stabek, A., Brown, S., \& Watters, P. A. (2009, July). The case for a consistent cyberscam classification framework (CCCF). In Ubiquitous, Autonomic and Trusted Computing, 2009. UICATC'O9. Symposia and Workshops on (pp. 525-530). IEEE.

xix. Sternberg, R. J. (1995). Love as a story. Journal of social and personal relationships, 12(4), 541-546.

xx. Sternberg, R. J. (1999). Love is a story: A new theory of relationships. Oxford University, USA .

xxi. Whitty, M. T., \& Buchanan, T. (2012). The online romance scam: A serious cybercrime. CyberPsychology, Behavior, and Social Networking, 15(3), 181-183. 